\title{
CARACTERÍSTICAS AGRONÔMICAS E RENDIMENTO DE SEMENTES DE SOJA NA SEMEADURA REALIZADA NO PERÍODO DE SAFRINHA ${ }^{(1)}$
}

\author{
ALESSANDRO DE LUCCA E BRACCINI ${ }^{(2,4)} ;$ IVO DE SÁ MOTTA $^{(2)} ;$ CARLOS ALBERTO SCAPIM $^{(2,4)}$; \\ MARIA DO CARMO LANA BRACCINI ${ }^{(3)}$; MARIZANGELA RIZZATTI ÁVILA ${ }^{(2)}$; \\ DANA KÁTIA MESCHEDE ${ }^{(2)}$
}

\begin{abstract}
RESUMO
Dentre os fatores que afetam o rendimento das sementes de soja, a definição da época de semeadura é fundamental para obter sementes de melhor qualidade e em maiores quantidades. O presente trabalho foi desenvolvido com o objetivo de avaliar o efeito da semeadura da soja (Glycine max (L.) Merrill) na época denominada "safrinha" nas características agronômicas das plantas e no rendimento de sementes de cinco cultivares. Foram desenvolvidos três experimentos de competição de cultivares em dois anos agrícolas (1998/99 e 1999/00), com delineamento em blocos completos casualizados, instalando-se um experimento em cada época de semeadura (15/11, 15/1 e 15/2). A semeadura realizada em novembro foi utilizada na comparação com os períodos de safrinha. As cultivares estudadas, bem como os respectivos grupos de maturação, foram os seguintes: 'BRS 132' (precoce), 'BRS 133' (semiprecoce), 'BR 16' (semiprecoce), 'BRS 134' (médio) e 'FT-Estrela' (tardio). No campo, foram realizadas as seguintes determinações: números de dias para a emergência, para o florescimento e para a maturação, grau de acamamento das plantas, altura de inserção das primeiras vagens, altura das plantas, número de vagens por planta, massa de mil sementes e rendimento de sementes. A semeadura realizada nos meses de janeiro e fevereiro não é alternativa viável para a produção quantitativa de sementes na Região de Maringá (PR), independentemente da duração de ciclo da cultivar de soja utilizada.
\end{abstract}

Palavras-chave: soja, sementes, época de semeadura, rendimento.

\section{ABSTRACT \\ AGRONOMIC TRAITS AND SEED PARAMETERS OF SOYBEAN CULTIVARS AS AFFECTED BY DELAYED SOWINGS}

Sowing date is one of the most important factors affecting soybean yielding potential. The main aim of this research work was to evaluate the effects of delayed sowings on soybean (Glycine max (L.) Merril) cultivar agronomic traits and seed yields. Experimental trials were carried out during the 1998/ 1999 and 1999/2000 growing seasons, using three sowing dates (November $15^{\text {th }}$, January $15^{\text {th }}$; and February $15^{\text {th }}$ ) and five soybean cultivars with different seed maturation periods (BRS-132: very early; BRS-133: early; BR-16: early; BRS-134: intermediate and FT-Estrela: late). A randomized complete block design, with three replications, was set up for each sowing date, the November sowing date considered as the reference. The following agronomic traits were scored: number of days from sowing to seedling emergence, full blooming and seed maturation; first pod insertion height; plant height and degree of laid-down plants as well as the seed parameters overall seed yields, number of pods per plant and mass of thousand

$\left({ }^{1}\right)$ Recebido para publicação em 12 de julho e aceito em 29 de dezembro de 2003.

$\left({ }^{2}\right)$ Departamento de Agronomia, Universidade Estadual de Maringá (UEM), Av. Colombo, 5790, 87020-900 Maringá (PR). E-mail: albraccini@uol.com.br

$\left(^{3}\right)$ Centro de Ciências Agrárias, Universidade Estadual do Oeste do Paraná (UNIOESTE), Rua Pernambuco, 1777, 85960000 Marechal Cândido Rondon (PR). E-mail: mclana@unioeste.br

$\left({ }^{4}\right)$ Com bolsa de produtividade em pesquisa do CNPq. 
seeds. The strong seed yield reductions in delayed sowings for all soybean cultivars (not talking into their flowering and/or seed maturation periods), in both growing seasons, regardless the seed maturation periods of soybean cultivars, as compared to the usual growing season (November), as well as other agronomic traits, clearly indicate the unfeasibility of delayed sowings at the region of Maringá, Paraná State, Brazil.

Key words: soybean, seeds, sowing date, yield.

\section{INTRODUÇÃO}

A cultura da soja é muito sensível ao comprimento do dia, ou melhor, à extensão do período de ausência de luz para a indução floral. Portanto, o efeito típico do fotoperíodo na soja, quando se leva uma variedade para regiões com menor latitude ou retarda sua semeadura, é a redução do período compreendido entre a emergência das plântulas e o início do florescimento e, conseqüentemente, do ciclo da cultura. Nessa circunstância ocorrem, também, reduções do porte das plantas, da altura de inserção de primeiras vagens, da área foliar e da produtividade (Green et al., 1965; Sediyama et al., 1972). Dentre os fatores que afetam o rendimento e a qualidade das sementes de soja pode-se mencionar a época de semeadura como fundamental (CosTA et al., 1995).

Alguns trabalhos confirmam que a época de semeadura deve ser estabelecida de tal forma que o estádio de maturação das sementes ocorra em condições de temperaturas mais amenas, associadas a baixos índices pluviométricos (França Neto e HenNing, 1984). Em consonância com essa afirmação, Pereira et al. (1979) observaram que, para as condições do Norte do Paraná, as variedades precoces semeadas no início de outubro produzem, muitas vezes, sementes de baixa qualidade fisiológica e com alto grau de deterioração por umidade, em virtude da maturação, prevista para a segunda quinzena de fevereiro, coincidir com períodos de elevada temperatura e excesso de chuvas.

VAL et al. (1985), trabalhando com nove cultivares de soja e cinco épocas de semeadura, concluíram que, de maneira geral, meados de novembro destacouse como a melhor época de semeadura para a região de Londrina (PR), quando as cultivares, em sua maioria, alcançaram as maiores produções e alturas de planta. A antecipação da semeadura para setembro prejudicou a maioria das cultivares, diminuindo o rendimento de grãos, a altura de planta e a inserção das vagens.

Tem sido notória a afirmação de que a semeadura fora da época preferencial ou recomendada pela pesquisa causa grandes prejuízos na produção e na qualidade das sementes, em virtude, principalmente, do maior ataque de percevejos. Aliado a este fator, o comprimento do dia ou fotoperíodo torna-se limitante para a cultura da soja, reduzindo significativamente o ciclo das cultivares, seu porte e, em conseqüência, rendimento de sementes.

Diversos trabalhos experimentais têm sido desenvolvidos, em inúmeras áreas produtoras de soja do país, com a finalidade de estabelecer a época de semeadura mais adequada para a produção de sementes (Melhorança e Mesquita, 1982; NaKagawa et al., 1983; VIEIRA et al., 1985; ZUFFO et al., 1987; BHERING et al., 1991a e b; Costa et al., 1995). Esses estudos apresentam uma importância muito grande, pois indicam a presença de um problema que deve ser investigado de maneira mais detalhada. Além disso, a grande extensão territorial do país, apresentando condições edafoclimáticas bastante distintas, a expansão da cultura da soja para novas regiões produtoras e o freqüente surgimento de variedades mais produtivas e mais bem adaptadas, justificam a realização deste tipo de trabalho, procurando estabelecer melhores condições para obter sementes em maior quantidade e com melhor qualidade fisiológica.

No Estado do Paraná, a semeadura de soja no período de entressafra ou "safrinha" tem sido mais freqüente na Região Oeste, em áreas com solo de alta fertilidade e outono-inverno mais úmido, em sucessão ao milho precoce colhido em janeiro. Embora alguns agricultores tenham obtido produções econômicas nesse sistema, a baixa produtividade média obtida por muitos deles, em alguns anos, revela que a semeadura tardia (safrinha) da soja pode ser considerada um cultivo de risco, caso não sejam desenvolvidas tecnologias adequadas para essa situação (EMBRAPA SOJA, 2001).

Em virtude de grande influência do comprimento do dia no desenvolvimento da soja, bem como da limitação de fotoperíodo para o desenvolvimento da cultura e de variedades mais bem adaptadas para o período de entressafra, acredita-se que essa recomendação pode estar fadada ao insucesso, caso não sejam pesquisadas e desenvolvidas novas tecnologias para seu cultivo. Outro problema relevante observado nesse período de outono-inverno tem sido o aspecto fitossanitário da cultura, em vista da elevada incidência de pragas e de doenças, principalmente percevejos, complexo de doenças de final de ciclo e oídio, fatores capazes de inviabilizarem o processo produtivo da cultura. 
O objetivo deste trabalho foi avaliar a influência da semeadura na época denominada "safrinha" nas características agronômicas das plantas e no rendimento de sementes de cinco cultivares de soja.

\section{MATERIAL E MÉTODOS}

O trabalho foi desenvolvido nos anos agrícolas de 1998/99 e de 1999/00, em área do Centro Técnico de Irrigação (CTI), pertencente ao Departamento de Agronomia da Universidade Estadual de Maringá (DAG/UEM), localizada na cidade de Maringá, Região Noroeste do Estado do Paraná, situado a $23^{\circ} 25^{\prime}$ de latitude sul, $51^{\circ} 57^{\prime}$ de longitude oeste e 542 metros de altitude. O solo do local é caracterizado como Latossolo Vermelho Distroférrico, com topografia suave ondulada e declividade média de $4 \%$. Pela classificação de Köeppen, o clima local é caracterizado como "Cfa", subtropical úmido, mesotérmico, de verão quente, com tendências a concentrar as chuvas no período de verão, mas sem estação seca definida (IAPAR, 1987). Os dados de precipitação pluvial, temperaturas máxima e mínima diárias e umidade relativa do ar, referentes aos períodos de duração dos experimentos, nos dois anos agrícolas, são apresentados nas tabelas 1 e 2 respectivamente.

Foram desenvolvidos três experimentos de competição de cultivares em cada ano agrícola, com cinco tratamentos e três repetições, com delineamento em blocos completos casualizados, instalando-se um experimento em cada época de semeadura $(15 / 11,15$ / 1 e 15/2). O cultivo na época preferencial (novembro) foi utilizado na comparação das épocas de semeadura tardias. As cultivares estudadas foram as seguintes: 'BRS 132' (precoce), 'BRS 133' (semiprecoce), 'BR 16' (semiprecoce), 'BRS 134' (médio) e 'FT-Estrela' (tardio). As parcelas foram constituídas de quatro linhas de 5 $\mathrm{m}$ de comprimento, espaçadas de $0,5 \mathrm{~m}$ entre si. $\mathrm{Na}$ colheita não foram consideradas as duas linhas externas, bem como $0,5 \mathrm{~m}$ de cada extremidade das linhas centrais por se tratarem de bordaduras.

O preparo do solo, a adubação e as demais práticas culturais foram as preconizadas pelo sistema de produção da região. O solo da área experimental foi analisado quanto às características químicas e a adubação, realizada de acordo com as recomendações da análise de solo (EMBrapa SOJA, 1999).

Duas semanas após a emergência das plantas foram realizados desbastes, deixando-se cerca de 20 plantas por metro linear. As plantas daninhas foram controladas por meio de aplicação de herbicidas e capinas manuais e o controle de lagartas, percevejos e outras pragas foi realizado, sempre que necessário, com pulverizações sistemáticas de inseticidas recomendados para cada espécie de inseto, até o fim do ciclo da cultura.

Durante o desenvolvimento da cultura foram avaliadas as seguintes características agronômicas: número de dias para a emergência, floração e maturação. $\mathrm{Na}$ época de maturação foram efetuadas determinações da altura de inserção das primeiras vagens, da altura média das plantas, do número de vagens por planta e do grau de acamamento das plantas.

Considerou-se o número de dias para a emergência o período compreendido da semeadura até $50 \%$ ou mais das plântulas no estádio VE, ou seja, com os cotilédones completamente acima do nível do solo. $\mathrm{O}$ número de dias para a floração compreendeu o período da emergência (estádio VE) até $50 \%$ das plantas da área útil no estádio R1, ou seja, plantas com pelo menos uma flor aberta na haste principal. O número de dias para a maturação referiu-se ao período compreendido da emergência (estádio VE) até $50 \%$ das plantas da área útil no estádio R8, ou maturação plena, conforme a escala proposta por FeHr et al. (1971).

Para determinar a altura de planta e a de inserção das primeiras vagens foram avaliadas dez plantas da área útil ao acaso, por parcela, com o auxílio de régua milimetrada de madeira e os resultados expressos em $\mathrm{cm}$. O número de vagens por planta foi avaliado na época de maturação (estádio R8), contando-se o número de vagens presentes em 10 plantas escolhidas aleatoriamente na área útil de cada parcela.

Para avaliar o grau de acamamento das plantas utilizou-se uma escala de notas variando de 1 a 5, conforme descrito a seguir: $1-0 \%$ ou nenhuma planta da área útil acamada/parcela; $2-25 \%$ das plantas da área útil acamadas/parcela; $3-50 \%$ das plantas da área útil acamadas/parcela; $4-75 \%$ das plantas da área útil acamadas / parcela e $5-100 \%$ das plantas da área útil acamadas/parcela.

As plantas foram colhidas manualmente, cinco a oito dias após o estádio R8 de desenvolvimento, ou seja, quando $95 \%$ das vagens apresentaram a coloração típica de vagem madura (FeHR et al., 1971). Partindo-se do rendimento de sementes nas parcelas, calculou-se a produtividade em kg.ha ${ }^{-1}$. Para o cálculo do rendimento, o grau de umidade das sementes, determinado por meio do método da estufa a $105^{\circ} \mathrm{C}$ $\pm 3{ }^{\circ} \mathrm{C}$ por 24 horas (BRASIL, 1992), foi corrigido para $13 \%$. Obteve-se a massa de mil sementes por meio da pesagem em laboratório de quatro subamostras de 100 sementes, para cada repetição de campo, com o auxílio de balança analítica com precisão de um miligrama. Os resultados foram multiplicados por 10 e expressos em miligramas, conforme as prescrições contidas nas Regras para Análise de Sementes (BRASIL, 1992). 
Tabela 1. Dados de temperaturas máxima e mínima, precipitação pluvial e umidade relativa do ar, em Maringá (PR), de outubro a junho do ano agrícola de 1998/99

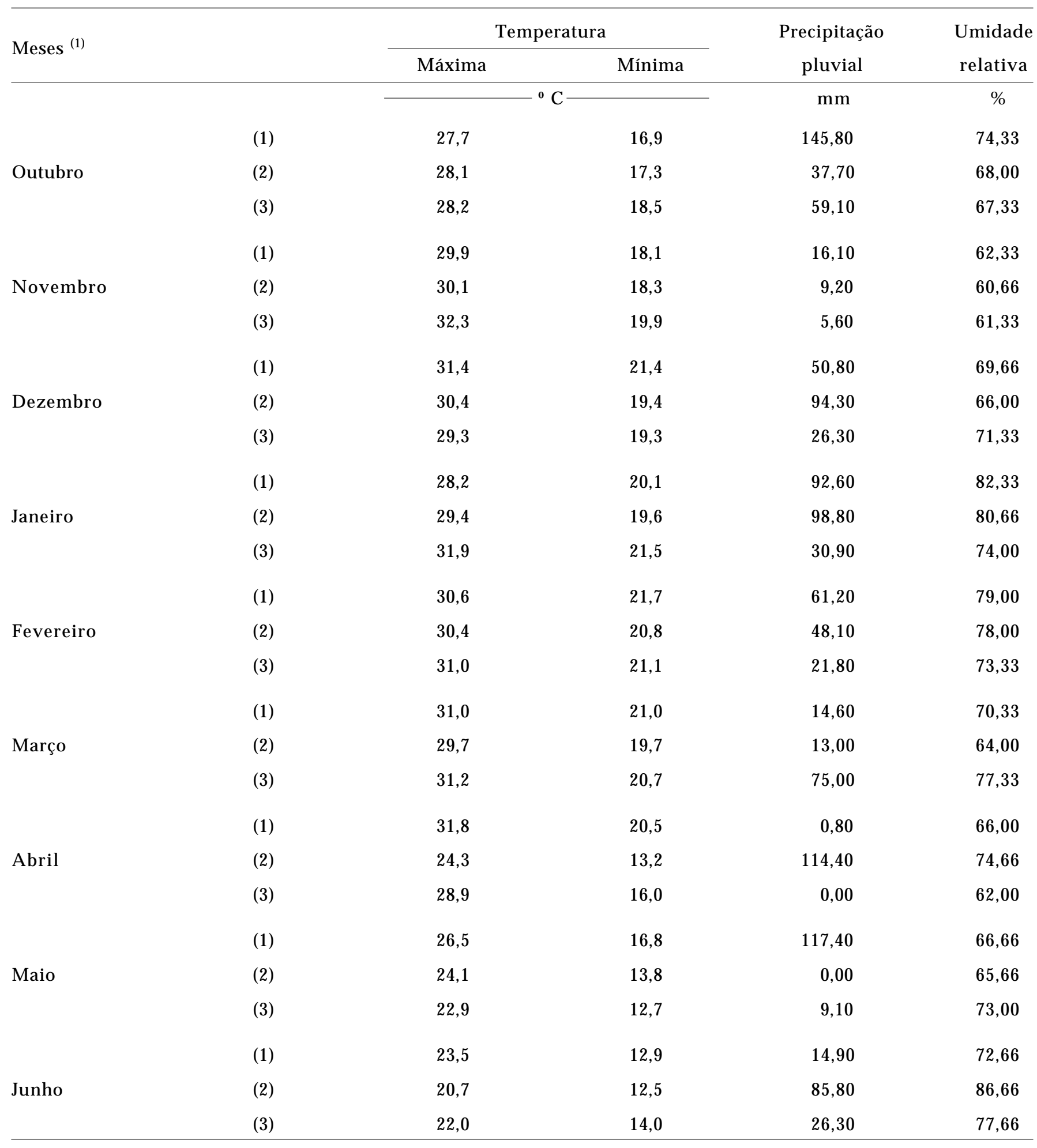

(1) (1), (2) e (3) representam os decêndios do mês. 
Tabela 2. Dados de temperaturas máxima e mínima, precipitação pluvial e umidade relativa do ar, em Maringá (PR), de outubro a junho do ano agrícola de 1999/00

\begin{tabular}{|c|c|c|c|c|c|}
\hline \multirow{2}{*}{ Meses ${ }^{(1)}$} & & \multicolumn{2}{|c|}{ Temperatura } & \multirow{2}{*}{$\begin{array}{c}\text { Precipitação } \\
\text { pluvial }\end{array}$} & \multirow{2}{*}{$\begin{array}{l}\text { Umidade } \\
\text { relativa }\end{array}$} \\
\hline & & Máxima & Mínima & & \\
\hline & & \multicolumn{2}{|c|}{${ }^{\circ} \mathrm{C}$} & $\mathrm{mm}$ & $\%$ \\
\hline \multirow{3}{*}{ Outubro } & (1) & 27,4 & 15,8 & 39,40 & 66,00 \\
\hline & (2) & 30,9 & 18,1 & 40,30 & 61,00 \\
\hline & (3) & 29,1 & 17,3 & 28,10 & 61,00 \\
\hline \multirow{3}{*}{ Novembro } & (1) & 27,3 & 17,3 & 36,30 & 67,66 \\
\hline & (2) & 28,5 & 16,1 & 4,70 & 58,00 \\
\hline & (3) & 32,2 & 18,8 & 5,70 & 46,33 \\
\hline \multirow{3}{*}{ Dezembro } & (1) & 31,4 & 19,0 & 115,40 & 67,33 \\
\hline & (2) & 29,9 & 20,1 & 72,20 & 60,00 \\
\hline & (3) & 31,7 & 20,9 & 93,30 & 64,33 \\
\hline \multirow{3}{*}{ Janeiro } & (1) & 30,3 & 19,7 & 147,40 & 73,66 \\
\hline & (2) & 31,8 & 21,3 & 89,30 & 74,00 \\
\hline & (3) & 30,8 & 20,8 & 6,10 & 64,33 \\
\hline \multirow{3}{*}{ Fevereiro } & (1) & 29,6 & 20,2 & 120,90 & 73,00 \\
\hline & (2) & 26,6 & 19,2 & 85,80 & 83,00 \\
\hline & (3) & 30,7 & 21,2 & 71,70 & 74,33 \\
\hline \multirow{3}{*}{ Março } & (1) & 28,9 & 20,3 & 43,30 & 77,66 \\
\hline & (2) & 28,4 & 19,7 & 34.5 & 74,66 \\
\hline & (3) & 29,7 & 19,5 & 52,50 & 72,66 \\
\hline \multirow{3}{*}{ Abril } & (1) & 30,6 & 20,3 & 0,00 & 59,00 \\
\hline & (2) & 28,6 & 18,6 & 31,50 & 65,66 \\
\hline & (3) & 28,0 & 17,4 & 0,50 & 58,33 \\
\hline \multirow{3}{*}{ Maio } & (1) & 26,3 & 16,7 & 11,30 & 67,66 \\
\hline & (2) & 23,7 & 14,4 & 11,90 & 67,66 \\
\hline & (3) & 23,2 & 13,3 & 14,60 & 65,66 \\
\hline \multirow{3}{*}{ Junho } & (1) & 24,8 & 16,5 & 4,80 & 67,33 \\
\hline & (2) & 24,8 & 17,1 & 33,00 & 70,00 \\
\hline & (3) & 18,3 & 16,1 & 68,80 & 65,66 \\
\hline
\end{tabular}

(1) (1), (2) e (3) representam os decêndios do mês. 
Os dados coletados foram submetidos à análise de variância conjunta e, na presença das interações significativas, procederam-se os desdobramentos necessários. As médias foram comparadas pelo teste de agrupamento de ScotT-KNOTT (1974) para avaliar o efeito de cultivares e de épocas de semeadura, a $5 \%$ de probabilidade.

\section{RESULTADOS E DISCUSSÃO}

A análise conjunta dos dados foi realizada para as três épocas de semeadura e dois anos agrícolas, uma vez que a razão entre o maior e o menor quadrado médio residual não foi superior a sete (BANZATto e KRONKA, 1995). Na análise conjunta, observou-se efeito significativo para a interação de segunda ordem (época de semeadura $\mathrm{x}$ cultivar $\mathrm{x}$ ano agrícola) para a maioria das características agronômicas avaliadas, com exceção do grau de acamamento das plantas, da altura de inserção das primeiras vagens e de planta, do número de vagens por planta e da massa de mil sementes. A presença dessa interação significativa mostra que as cultivares apresentaram resposta diferenciada em relação às épocas de semeadura em cada ano agrícola.

Na tabela 3 estão relacionados os resultados do desdobramento da interaçãa cultivares $x$ épocas de semeadura, em cada ano agrícola, referentes às determinações do número de dias para emergência, florescimento e maturação das plantas de soja. O número de dias para a emergência foi estatisticamente superior na semeadura realizada em novembro, em comparação com as semeaduras de janeiro e fevereiro. Não houve diferença significativa $(p>0,05)$ para essa característica nas semeaduras realizadas no período de "safrinha" (janeiro e fevereiro), nos dois anos agrícolas, exceto para as cultivares BR 16 e FT-Estrela no primeiro ano agrícola (Tabela 3A). Esse fato esteve relacionado, provavelmente, com a elevação da temperatura do solo, pois nessa circunstância, de acordo com Popinigis (1985), ocorre aumento na atividade metabólica das sementes e conseqüente maior velocidade de emergência das plântulas. Contudo, esta influência está intimamente relacionada com o potencial hídrico do solo e a condição fisiológica das sementes.

As cultivares que apresentaram maior duração do estádio vegetativo (Tabela 3B) foram FT-Estrela e BRS-133, em praticamente todas as épocas de semeadura avaliadas. Esses resultados estão coerentes com as características desses materiais, uma vez que a cultivar FT-Estrela pertence ao grupo de maturação tardio e BRS-133 apresenta-se dotada de maior período de juvenilidade.
Os resultados do desdobramento da interação cultivares $x$ épocas de semeadura em cada ano agrícola, para a característica número de dias para maturação encontram-se ilustrados na tabela 3C. Observa-se que a cultivar FT-Estrela, pertencente ao grupo de maturação tardio, foi a que apresentou maior ciclo em todas as épocas de semeadura avaliadas, fato esperado pela sua própria característica em relação às demais utilizadas.

As cultivares BRS-134 e BRS-133 apresentaram ciclos intermediários e BRS-132 e BR-16 foram as mais precoces em todas as épocas de semeadura avaliadas, indicando comportamento bastante similar entre elas. Os dados da tabela $3 \mathrm{C}$ revelam que houve redução acentuada no ciclo de todas as cultivares, nos dois anos agrícolas, com o atraso da época de semeadura. Considerando que a soja é planta de dias curtos, a redução do período compreendido entre a emergência e a maturação foi conseqüência do fotoperíodismo (ABEL, 1961; GREEN et al., 1965). Esse resultado está coerente com o trabalho realizado por BHÉRING et al. (1991a).

A redução observada no número de dias para o florescimento e a maturação das plantas (Tabela 3) das cinco cultivares avaliadas neste experimento, quando se retardou a semeadura, foi responsável, também, pela redução das demais características agronômicas (Tabela 5). Houve grande variabilidade nas características de crescimento das plantas em relação ao ano agrícola avaliado.

Na tabela 4 é apresentado o número médio de plantas por metro obtido na avaliação do estande final. Observa-se que o estande final de plantas foi mantido uniforme com cerca de 20 plantas por metro, ou seja, praticamente não houve diferença significativa $(p>0,05)$ para todas as cultivares e épocas de semeadura, com exceção da BRS 132 cujo estande final obtido na semeadura de janeiro foi superior estatisticamente àquele avaliado nas semeaduras de novembro e fevereiro, no primeiro ano agrícola.

No entanto, para BR 16, nesse mesmo ano agrícola, o número de plantas por metro obtido nas semeaduras de novembro e fevereiro foi superior ao da semeadura de janeiro. Considerando-se que o espaçamento utilizado entre linhas foi de $0,5 \mathrm{~m}$, obteve-se uma população final de aproximadamente 400 mil plantas por hectare, estando de acordo com as recomendações preconizadas pela EMBRAPA SOJA (1999).

Os resultados obtidos na avaliação de grau de acamamento, altura de inserção das primeiras vagens, altura média das plantas e número de vagens por planta, nas três épocas de semeadura e dois anos agrícolas avaliados estão relacionados na tabela 5 . 
Tabela 3. Médias estimadas do número de dias para a emergência (A), florescimento (B) e maturação (C) das plantas de cinco cultivares de soja, em três épocas de semeadura e dois anos agrícolas, em Maringá (PR)

\begin{tabular}{|c|c|c|c|c|c|c|c|c|}
\hline \multirow{3}{*}{ Cultivar } & \multicolumn{3}{|c|}{ Ano agrícola 1998/99 } & \multirow{3}{*}{ Média } & \multirow{2}{*}{\multicolumn{3}{|c|}{$\begin{array}{l}\text { Ano agrícola 1999/00 } \\
\text { Época de semeadura }\end{array}$}} & \multirow{3}{*}{$\begin{array}{c}\text { A } \\
\text { Média }\end{array}$} \\
\hline & \multicolumn{3}{|c|}{ Época de semeadura } & & & & & \\
\hline & $15 / 11$ & $15 / 1$ & $15 / 2$ & & $15 / 11$ & $15 / 1$ & $15 / 2$ & \\
\hline BRS 132 & 5,67 Aa & $4,00 \mathrm{Bc}$ & $4,00 \mathrm{Bb}$ & 4,56 & $6,00 \mathrm{Aa}$ & $4,33 \mathrm{Bb}$ & $4,33 \mathrm{Bb}$ & 4,89 \\
\hline BRS 133 & 6,33 Aa & $4,00 \mathrm{Bc}$ & $4,00 \mathrm{Bb}$ & 4,78 & $6,00 \mathrm{Aa}$ & $5,00 \mathrm{Ba}$ & $5,00 \mathrm{Ba}$ & 5,33 \\
\hline BRS 134 & $6,00 \mathrm{Aa}$ & $4,00 \mathrm{Bc}$ & $4,33 \mathrm{Bb}$ & 4,78 & $6,00 \mathrm{Aa}$ & $4,00 \mathrm{Bb}$ & $4,00 \mathrm{Bb}$ & 4,67 \\
\hline BR 16 & 5,67 Aa & 5,67 Aa & $5,00 \mathrm{Ba}$ & 5,45 & $6,00 \mathrm{Aa}$ & $5,00 \mathrm{Ba}$ & $5,00 \mathrm{Ba}$ & 5,33 \\
\hline FT-Estrela & 5,67 Aa & $4,67 \mathrm{Bb}$ & $4,00 \mathrm{Cb}$ & 4,78 & $6,00 \mathrm{Aa}$ & $4,67 \mathrm{Ba}$ & $5,00 \mathrm{Ba}$ & 5,22 \\
\hline Média & 5,87 & 4,47 & 4,27 & & 6,00 & 4,60 & 4,67 & \\
\hline
\end{tabular}

C.V. $(\%)$

7,18

\begin{tabular}{|c|c|c|c|c|c|c|c|c|}
\hline \multirow{3}{*}{ Cultivar } & \multicolumn{3}{|c|}{ Ano agrícola 1998/99 } & \multirow{3}{*}{ Média } & \multirow{2}{*}{\multicolumn{3}{|c|}{$\begin{array}{l}\text { Ano agrícola 1999/00 } \\
\text { Época de semeadura }\end{array}$}} & \multirow{3}{*}{$\begin{array}{c}\text { B } \\
\text { Média }\end{array}$} \\
\hline & \multicolumn{3}{|c|}{ Época de semeadura } & & & & & \\
\hline & $15 / 11$ & $15 / 1$ & $15 / 2$ & & $15 / 11$ & $15 / 1$ & $15 / 2$ & \\
\hline BRS 132 & $45,67 \mathrm{Ad}$ & $36,67 \mathrm{Bc}$ & $31,33 \mathrm{Cc}$ & 37,89 & $45,67 \mathrm{Ac}$ & $39,67 \mathrm{Bd}$ & 31,67 Cc & 39,00 \\
\hline BRS 133 & $55,67 \mathrm{Ab}$ & $40,33 \mathrm{Ba}$ & $39,33 \mathrm{Cb}$ & 45,11 & $51,33 \mathrm{Aa}$ & $42,67 \mathrm{Bb}$ & $35,00 \mathrm{Ca}$ & 43,00 \\
\hline BRS 134 & $52,67 \mathrm{Ac}$ & $39,00 \mathrm{Bb}$ & $38,67 \mathrm{Bb}$ & 43,45 & $48,00 \mathrm{Ab}$ & $41,33 \mathrm{Bc}$ & $34,00 \mathrm{Cb}$ & 41,11 \\
\hline BR 16 & 43,33 Ae & $34,00 \mathrm{Bd}$ & $30,00 \mathrm{Cd}$ & 35,78 & $45,67 \mathrm{Ac}$ & $38,33 \mathrm{Be}$ & $29,00 \mathrm{Cd}$ & 37,67 \\
\hline FT-Estrela & $59,00 \mathrm{Aa}$ & $39,67 \mathrm{Cb}$ & $41,33 \mathrm{Ba}$ & 46,67 & $50,67 \mathrm{Aa}$ & $44,00 \mathrm{Ba}$ & $35,67 \mathrm{Ca}$ & 43,45 \\
\hline Média & 51,27 & 37,93 & 36,13 & & 48,27 & 41,20 & 33,07 & \\
\hline
\end{tabular}

C.V. $(\%) \quad 1,40$

\begin{tabular}{|c|c|c|c|c|c|c|c|c|}
\hline \multirow{3}{*}{ Cultivar } & \multicolumn{3}{|c|}{ Ano agrícola 1998/99 } & \multirow{3}{*}{ Média } & \multirow{2}{*}{\multicolumn{3}{|c|}{$\frac{\text { Ano agrícola 1999/00 }}{\text { Época de semeadura }}$}} & \multirow{3}{*}{$\begin{array}{c}\text { C } \\
\text { Média }\end{array}$} \\
\hline & \multicolumn{3}{|c|}{ Época de semeadura } & & & & & \\
\hline & $15 / 11$ & $15 / 1$ & $15 / 2$ & & $15 / 11$ & $15 / 1$ & $15 / 2$ & \\
\hline BRS 132 & $114,67 \mathrm{Ad}$ & $109,00 \mathrm{Bc}$ & $105,00 \mathrm{Cb}$ & 109,56 & 118,33 Ac & $97,67 \mathrm{Bc}$ & $85,67 \mathrm{Cc}$ & 100,56 \\
\hline BRS 133 & $118,00 \mathrm{Ac}$ & $113,33 \mathrm{Bb}$ & $105,33 \mathrm{Cb}$ & 112,22 & $122,33 \mathrm{Ab}$ & $101,67 \mathrm{Bb}$ & $91,33 \mathrm{Cb}$ & 105,11 \\
\hline BRS 134 & $120,33 \mathrm{Ab}$ & $113,67 \mathrm{Bb}$ & $108,67 \mathrm{Ca}$ & 114,22 & $124,00 \mathrm{Ab}$ & $103,00 \mathrm{Bb}$ & $92,67 \mathrm{Cb}$ & 106,56 \\
\hline BR 16 & $114,67 \mathrm{Ad}$ & $108,33 \mathrm{Bc}$ & $106,00 \mathrm{Cb}$ & 109,67 & $117,00 \mathrm{Ac}$ & $99,00 \mathrm{Bc}$ & $87,33 \mathrm{Cc}$ & 101,11 \\
\hline FT-Estrela & $135,00 \mathrm{Aa}$ & $118,67 \mathrm{Ba}$ & $109,00 \mathrm{Ca}$ & 120,89 & $136,67 \mathrm{Aa}$ & $105,00 \mathrm{Ba}$ & $95,33 \mathrm{Ca}$ & 112,33 \\
\hline Média & 120,53 & 112,60 & 106,80 & & 123,67 & 101,27 & 90,47 & \\
\hline C.V. $(\%)$ & & & & 1,14 & & & & \\
\hline
\end{tabular}

Médias seguidas de mesma letra maiúscula na linha ou minúscula na coluna pertencem a um mesmo grupo, de acordo com o critério de agrupamento de Scott-Knott (1974), a 5\% de probabilidade. 
Tabela 4. Médias estimadas do número de plantas por metro, obtidas na avaliação do estande final de cinco cultivares de soja, em três épocas de semeadura e dois anos agrícolas, em Maringá (PR)

\begin{tabular}{|c|c|c|c|c|c|c|c|c|}
\hline \multirow{3}{*}{ Cultivar } & \multicolumn{3}{|c|}{ Ano agrícola 1998/99 } & \multirow{3}{*}{ Média } & \multirow{2}{*}{\multicolumn{3}{|c|}{$\begin{array}{l}\text { Ano agrícola } 1999 / 00 \\
\text { Época de semeadura }\end{array}$}} & \multirow{3}{*}{ Média } \\
\hline & \multicolumn{3}{|c|}{ Época de semeadura } & & & & & \\
\hline & $15 / 11$ & $15 / 1$ & $15 / 2$ & & $15 / 11$ & $15 / 1$ & $15 / 2$ & \\
\hline BRS 132 & $19,67 \mathrm{Ba}$ & $22,33 \mathrm{Aa}$ & $20,33 \mathrm{Ba}$ & 20,78 & $20,67 \mathrm{Aa}$ & $20,00 \mathrm{Aa}$ & $20,00 \mathrm{Aa}$ & 20,22 \\
\hline BRS 133 & $20,00 \mathrm{Aa}$ & $18,67 \mathrm{Ab}$ & $20,67 \mathrm{Aa}$ & 19,78 & $20,33 \mathrm{Aa}$ & $20,67 \mathrm{Aa}$ & $20,67 \mathrm{Aa}$ & 20,56 \\
\hline BRS 134 & $18,67 \mathrm{Ba}$ & $21,67 \mathrm{Aa}$ & $20,67 \mathrm{Aa}$ & 20,34 & $21,00 \mathrm{Aa}$ & $20,67 \mathrm{Aa}$ & $20,67 \mathrm{Aa}$ & 20,78 \\
\hline BR 16 & $21,00 \mathrm{Aa}$ & $16,67 \mathrm{Bb}$ & $20,00 \mathrm{Aa}$ & 19,22 & $20,33 \mathrm{Aa}$ & $20,67 \mathrm{Aa}$ & $19,67 \mathrm{Aa}$ & 20,22 \\
\hline FT-Estrela & $18,00 \mathrm{Aa}$ & $19,00 \mathrm{Ab}$ & $20,67 \mathrm{Aa}$ & 19,22 & $21,67 \mathrm{Aa}$ & $20,67 \mathrm{Aa}$ & $20,67 \mathrm{Aa}$ & 21,00 \\
\hline Média & 19,47 & 19,67 & 20,47 & & 20,80 & 20,54 & 20,34 & \\
\hline C.V.(\%) & & & & 6,70 & & & & \\
\hline
\end{tabular}

Médias seguidas de mesma letra maiúscula na linha ou minúscula na coluna pertencem a um mesmo grupo, de acordo com o critério de agrupamento de Scott-Knott (1974), a 5\% de probabilidade.

A análise de variância conjunta dos dados revelou efeito não significativo $(p>0,05)$ para a interação cultivar $x$ época de semeadura $x$ ano agrícola. Apenas os efeitos principais e a interação época $\mathrm{x}$ ano foram significativos $(\mathrm{p}<0,05)$ para tais características. Observou-se comportamento similar para a altura de planta e o grau de acamamento, à medida que se retardou a época de semeadura, ou seja, naquela realizada em novembro foi favorecido o crescimento da soja, permitindo a obtenção de plantas mais altas, porém mais suscetíveis à ocorrência de acamamento. Resultados semelhantes foram obtidos por Melhorança e Mesquita (1982) e Bhéring et al. (1991a). Geralmente, semeaduras mais tardias resultam em plantas com menor altura, quando comparadas com aquelas realizadas na época recomendada para a cultura de soja (SANTOS e EstefAnEL, 1971; LAW e BYTH, 1973).

As maiores alturas de planta têm sido obtidas com a semeadura realizada entre o fim de outubro e o de novembro no Estado do Paraná (EMBRAPa SOJA, 1999).

No que diz respeito ao desdobramento da interação épocas de semeadura em cada ano agrícola para a altura de inserção da primeira vagem e o número de vagens por planta, verificou-se de modo geral, que houve redução nessas características com o retardamento da época de semeadura, com exceção do segundo ano agrícola em que não houve diferença significativa $(p>0,05)$ na altura de inserção das primeiras vagens entre as semeaduras de novembro e janeiro. De forma geral, a altura de inserção obtida nas épocas de semeadura de safrinha não foram compatíveis para a colheita mecanizada (Tabela 5C). A semeadura realizada na época recomendada pela pesquisa permitiu a obtenção de plantas com características agronômicas mais desejáveis. Esses resultados estão de acordo com os obtidos por Melhorança e Mesquita (1982); Vieira et al. (1985); NAKagawa et al. (1988); BhÉRING et al. (1991a); Medina et al. (1997); MARCHIORI et al. (1999); MARTINS et al., (1999).

Para a característica massa de mil sementes, a interação de segunda ordem não foi significativa ( $p$ $>0,05)$. Apenas os efeitos principais e as interações de primeira ordem foram significativos $(p<0,05)$. $\mathrm{Na}$ tabela 6 são apresentados os resultados do desdobramento da interação época de semeadura $x$ ano agrícola e de cultivar $x$ ano agrícola. Observa-se que a massa de mil sementes foi significativamente $(\mathrm{p}<0,05)$ reduzida apenas na semeadura realizada em fevereiro. Não houve diferença estatística quanto à característica em questão para as semeaduras de novembro e janeiro, nos dois anos agrícolas avaliados (Tabela 6A).

O comportamento das cinco cultivares quanto à massa de mil sementes revela que a cultivar BR 16 apresentou maiores valores médios para essa característica. Não houve diferença significativa ( $p>$ 0,05 ) entre as demais cultivares com referência a essa característica, exceto para BRS 132 que apresentou a maior massa juntamente com o BR 16, no primeiro ano agrícola (Tabela 6B). 
Tabela 5. Médias estimadas do grau de acamamento das plantas (A), altura de planta (B), altura de inserção das primeiras vagens $(C)$ e número de vagens por planta (D) de soja, em três épocas de semeadura e dois anos agrícolas, em Maringá (PR)

\begin{tabular}{lccc}
\hline Época de semeadura & Ano agrícola & Ano agrícola & A \\
\cline { 2 - 3 } & $1998 / 99$ & $1999 / 00$ & $1,20 \mathrm{Ba}$ \\
\cline { 3 - 4 } $15 / 11$ & $2,63 \mathrm{Aa}$ & $1,40 \mathrm{Aa}$ & 1,92 \\
$15 / 1$ & $1,33 \mathrm{Ab}$ & $1,00 \mathrm{Ab}$ & 1,37 \\
$15 / 2$ & $1,07 \mathrm{Ac}$ & 1,20 & 1,04 \\
\hline Média & 1,68 & 1,20 \\
\hline
\end{tabular}

$\begin{array}{ll}\text { C.V. }(\%) & 24,78\end{array}$

\begin{tabular}{lccc}
\hline \multirow{2}{*}{ Época de semeadura } & Ano agrícola & Ano agrícola & B \\
\cline { 2 - 3 } & $1998 / 99$ & $1999 / 00$ & Média \\
\hline $15 / 11$ & $97,53 \mathrm{Aa}$ & $71,12 \mathrm{Ba}$ & 84,33 \\
$15 / 1$ & $50,74 \mathrm{Ab}$ & $52,43 \mathrm{Ab}$ & 51,59 \\
$15 / 2$ & $29,04 \mathrm{Bc}$ & $38,81 \mathrm{Ac}$ & 33,93 \\
\hline Média & 59,10 & 54,12 & \\
\hline C.V. $(\%)$ & & 9,19 & \\
\hline
\end{tabular}

\begin{tabular}{lccc}
\hline Época de semeadura & Ano agrícola & Ano agrícola & C \\
\cline { 2 - 3 } & $1998 / 99$ & $1999 / 00$ & Média \\
\hline $15 / 11$ & $10,21 \mathrm{Ba}$ & $11,65 \mathrm{Aa}$ & 10,93 \\
$15 / 1$ & $7,22 \mathrm{Bb}$ & $11,33 \mathrm{Aa}$ & 9,28 \\
$15 / 2$ & $6,36 \mathrm{Bc}$ & $8,45 \mathrm{Ab}$ & 7,41 \\
\hline Média & 7,93 & 10,48 & \\
\hline
\end{tabular}

C.V. $(\%)$

12,22

\begin{tabular}{lccc}
\hline \multirow{2}{*}{ Época de semeadura } & Ano agrícola & Ano agrícola & D \\
\cline { 2 - 3 } & $1998 / 99$ & $1999 / 00$ & Média \\
\hline $15 / 11$ & $58,99 \mathrm{Aa}$ & $30,61 \mathrm{Ba}$ & 44,80 \\
$15 / 1$ & $25,64 \mathrm{Ab}$ & $24,97 \mathrm{Ab}$ & 25,31 \\
$15 / 2$ & $11,70 \mathrm{Bc}$ & $18,30 \mathrm{Ac}$ & 15,00 \\
\hline Média & 32,11 & 24,63 & \\
\hline
\end{tabular}

C.V. (\%) 19,35

Médias seguidas de mesma letra maiúscula, em cada linha, não diferem entre si pelo teste $\mathrm{F}$, a $5 \%$ de probabilidade.

Médias seguidas de mesma letra minúscula, em cada coluna, pertencem a um mesmo grupo, de acordo com o critério de agrupamento de Scott-Knott (1974), a 5\% de probabilidade. 
Tabela 6. Médias estimadas da massa de mil sementes de soja, em miligramas, em três épocas de semeadura e dois anos agrícolas (A) e de cinco cultivares e dois anos agrícolas (B), em Maringá (PR)

\begin{tabular}{|c|c|c|c|}
\hline & Ano agrícola & Ano agrícola & A \\
\hline Época de semeadura & 1998/99 & 1999/00 & Média \\
\hline $15 / 11$ & $159,42 \mathrm{Aa}$ & $157,06 \mathrm{Aa}$ & 158,24 \\
\hline $15 / 01$ & $159,14 \mathrm{Aa}$ & $156,34 \mathrm{Aa}$ & 157,74 \\
\hline $15 / 02$ & $127,64 \mathrm{Bb}$ & $148,09 \mathrm{Ab}$ & 137,87 \\
\hline Média & 148,73 & 153,83 & \\
\hline
\end{tabular}

C.V. $(\%)$

3,84

\begin{tabular}{|c|c|c|c|}
\hline & Ano agrícola & Ano agrícola & B \\
\hline Cultivar & $1998 / 99$ & $1999 / 00$ & Média \\
\hline BRS 132 & $153,68 \mathrm{Aa}$ & $151,85 \mathrm{Ab}$ & 152,77 \\
\hline BRS 133 & $143,39 \mathrm{Ab}$ & $146,64 \mathrm{Ab}$ & 145,02 \\
\hline BRS 134 & $142,02 \mathrm{Bb}$ & $148,49 \mathrm{Ab}$ & 145,26 \\
\hline BR 16 & $158,80 \mathrm{Ba}$ & $171,42 \mathrm{Aa}$ & 165,11 \\
\hline FT-Estrela & $145,77 \mathrm{Ab}$ & $150,75 \mathrm{Ab}$ & 148,26 \\
\hline Média & 148,73 & 153,83 & \\
\hline
\end{tabular}

Médias seguidas de mesma letra maiúscula, em cada linha, não diferem entre si pelo teste $\mathrm{F}$, a 5\% de probabilidade.

Médias seguidas de mesma letra minúscula, em cada coluna, pertencem a um mesmo grupo, de acordo com o critério de agrupamento de Scott-Knott (1974), a 5\% de probabilidade.

Tabela 7. Médias estimadas do rendimento de sementes, em kg.ha-1, de cinco cultivares de soja, em três épocas de semeadura e dois anos agrícolas, em Maringá (PR)

\begin{tabular}{|c|c|c|c|c|c|c|c|c|}
\hline \multirow{3}{*}{ Cultivar } & \multicolumn{3}{|c|}{ Ano agrícola 1998/99 } & \multirow{3}{*}{ Média } & \multicolumn{3}{|c|}{ Ano agrícola 1999/00 } & \multirow{3}{*}{ Média } \\
\hline & \multicolumn{3}{|c|}{ Época de semeadura } & & \multicolumn{3}{|c|}{ Época de semeadura } & \\
\hline & $15 / 11$ & $15 / 1$ & $15 / 2$ & & $15 / 11$ & $15 / 1$ & $15 / 2$ & \\
\hline BRS 132 & $3229,17 \mathrm{Ab}$ & $1266,24 \mathrm{Ba}$ & $283,65 \mathrm{Ca}$ & 1593,02 & $3776,80 \mathrm{Aa}$ & $2402,71 \mathrm{Ba}$ & $1176,96 \mathrm{Cb}$ & 2452,16 \\
\hline BRS 133 & $4424,80 \mathrm{Aa}$ & $1320,80 \mathrm{Ba}$ & $673,89 \mathrm{Ca}$ & 2139,83 & $3944,68 \mathrm{Aa}$ & $2413,10 \mathrm{Ba}$ & $1725,76 \mathrm{Ca}$ & 2694,51 \\
\hline BRS 134 & $3431,09 \mathrm{Ab}$ & $1233,99 \mathrm{Ba}$ & $572,75 \mathrm{Ca}$ & 1746,94 & $3530,95 \mathrm{Aa}$ & $2741,37 \mathrm{Ba}$ & $1599,32 \mathrm{Ca}$ & 2623,88 \\
\hline BR 16 & $3086,60 \mathrm{Ab}$ & $897,72 \mathrm{Bb}$ & $300,72 \mathrm{Ca}$ & 1428,35 & $3052,21 \mathrm{Ab}$ & $2618,11 \mathrm{Ba}$ & $1354,57 \mathrm{Cb}$ & 2341,63 \\
\hline FT-Estrela & 2593,36 Ac & $891,39 \mathrm{Bb}$ & $441,00 \mathrm{Ca}$ & 1308,58 & $3547,35 \mathrm{Aa}$ & $2212,13 \mathrm{Ba}$ & $1206,77 \mathrm{Cb}$ & 2322,08 \\
\hline Média & 3353,00 & 1122,03 & 454,40 & & 3570,40 & 2477,48 & 1412,68 & \\
\hline
\end{tabular}

C.V. $(\%)$

11,78

Médias seguidas de mesma letra maiúscula na linha ou minúscula na coluna pertencem a um mesmo grupo, de acordo com o critério de agrupamento de Scott-Knott (1974), a 5\% de probabilidade.

$\mathrm{Na}$ tabela 7 estão relacionados os resultados obtidos para o rendimento de sementes das cinco cultivares de soja nas três épocas de semeadura e nos dois anos agrícolas. A análise de variância revelou significância para a interação época de semeadura $x$ cultivar $\mathrm{x}$ ano agrícola. Observa-se que o retardamento da época de semeadura provocou redução no rendimento de sementes de todas as cultivares nos dois anos agrícolas avaliados. Esse fato ocorreu, provavelmente, em função das condições climáticas observadas nesse período de safrinha no Estado do Paraná, onde as semeaduras mais tardias geralmente coincidem com períodos de estiagem e temperaturas mais amenas nos estádios mais críticos da cultura, ou seja, do florescimento ao enchimento dos grãos (Tabelas 1 e 2). 
Esses resultados estão de acordo com aqueles obtidos por Pегхото et al. (2000), em que os autores observaram que a época de semeadura é o fator que mais influencia no rendimento de grãos da soja.

\section{CONCLUSÃO}

Os resultados permitiram concluir que a semeadura realizada em janeiro e fevereiro não é alternativa viável para a produção quantitativa de sementes na Região de Maringá (PR), independentemente da duração de ciclo da cultivar de soja utilizada.

\section{REFERÊNCIAS}

ABEL, G.H. Response of soybeans to dates of planting in the Imperial Valley of California. Agronomy Journal, Madison, v.53, n.2, p.95-98, 1961.

BANZATTO, D.A.; KRONKA, S. N. Experimentação Agrícola. 3 ed. Jaboticabal: FUNEP, 1995. 247 p.

BHÉRING, M.C.; REIS, M.S.; SEDIYAMA, T.; SEDIYAMA, C.S.; ANDRADE, M.A.S. Influência de épocas de plantio sobre algumas características agronômicas da soja (Glycine max (L.) Merrill). Revista Ceres, Viçosa, v.38, n.219, p.396-408, 1991a.

BHÉRING, M.C.; REIS, M.S.; SEDIYAMA, C.S..; SEDIYAMA, T.; ANDRADE, M.A.S. Influência de épocas de plantio sobre a qualidade fisiológica das sementes de soja (Glycine max (L.) Merrill). Revista Ceres, Viçosa, v.38, n.219, p.409-421, 1991 b.

BRASIL. Ministério da Agricultura e Reforma Agrária. Regras para análise de sementes. Brasília: DNDV/SNAD/ CLAV, 1992. 365p.

COSTA, N.P.; FRANÇA NETO, J.B.; HENNING, A.A.; KRZYZANOWSKI, F.C.; CABRAL, N.T.; MENDES, M.C. Efeito da época de semeadura sobre a qualidade fisiológica de sementes de soja no Estado do Mato Grosso. Revista Brasileira de Sementes, Brasília, v.17, n.1, p.107-112, 1995.

EMBRAPA SOJA. Recomendações técnicas para a cultura da soja no Paraná 1999/2000. Londrina: Embrapa Soja, 1999. 236p. (Documentos, 131)

EMBRAPA SOJA. Tecnologias de produção de soja - Paraná 2001/2002. Londrina: Embrapa Soja, 2001. 281p. (Documentos, 166)

FEHR, W.R.; CAVINESS, C.E.; GURMOOD, D.T.; PENNINGTON, J.S. Stage of development description for soybean, Glycine max (L.) Merrill. Crop Science, Madison, v.11, n.6, p.929-931, 1971.

FRANÇA NETO, J.B.; HENNING, A.A. Qualidade fisiológica e sanitária de sementes de soja. Londrina: EMBRAPA-CNPSo, 1984. 39p. (Circular Técnica, 9)
GREEN, D.E.; PINNEL, C.L.; CAVANAN, L.E.; WILLIANS, L.F. Effect of planting date and maturity date on soybean seed quality. Agronomy Journal, Madison, v.57, n.2, p.165-168, 1965.

IAPAR. Cartas climáticas básicas do Estado do Paraná. Londrina: Instituto Agronômico do Paraná, 1987. 35p.

LAW, R.J.; BYTH, D.E. Response of soybeans to planting date in South Easten Queesland. 2. Vegetative end reprodutive development. Australian Journal of Agricultural Research, Melbourne, v.24, n.1, p.67-80, 1973.

MARCHIORI, L.F.S.; CÂMARA, G.M.S.; PEIXOTO, C.P.; MARTINS, M.C. Desempenho vegetativo de cultivares de soja [Glycine max (L.) Merrill] em épocas normal e safrinha. Scientia Agricola, Piracicaba, v.56, n.2, p.383-390, 1999.

MARTINS, M.C.; CÂMARA, G.M.S.; PEIXOTO, C.P.; MARCHIORI, L.F.S.; LEONARDO, V.; MATTIAZZI, P. Épocas de semeadura, densidade de plantas e desempenho vegetativo de cultivares de soja. Scientia Agricola, Piracicaba, v.56, n.4, p851-858, 1999.

MEDINA, P.F.; RAZERA, L.F.; MARCOS FILHO, J. \& BORTOLETTO, N. Produção de sementes de cultivares precoces de soja em duas épocas e dois locais paulistas: I. Características agronômicas e produtividade. Bragantia, Campinas, v.56, n.2, p.291-303, 1997.

MELHORANÇA, A.L.; MESQUITA, A.N. Efeito do espaçamento e épocas de semeadura sobre o rendimento e características agronômicas da soja em Dourados, MS. Pesquisa Agropecuária Brasileira, Brasília, v.17, n.5, p.729-732, 1982.

NAKAGAWA, J.; ROSOLEM, C.A.; MACHADO, J.R. Épocas de semeadura da soja. I. Efeitos na produção de grãos e nos componentes da produção. Pesquisa Agropecuária Brasileira, Brasília, v.18, n.11, p.1187-1198, 1983.

NAKAGAWA, J.; MACHADO, J.R.; ROSOLEM, C.A. Efeito da densidade de plantas no comportamento de cultivares de soja, em duas épocas de semeadura. Pesquisa Agropecuária Brasileira, Brasília, v.23, n.9, p.1003-1014, 1988.

PEIXOTO, C.P.; CÂMARA, G.M.S.; MARTINS, M.C; MARCHIORI, L.F.S.; GUERZONI, R.A.; MATTIAZZI, P. Época de semeadura e densidade de plantas de soja: I. Componentes da produção e rendimento de grãos. Scientia Agrícola, Piracicaba, v.57, n.1, p.89-96, 2000.

PEREIRA, L.A.G.; COSTA, N.P.; QUEIROZ, E.F.; NEUMAIER, N.; TORRES, E. Efeito da época de semeadura sobre a qualidade de sementes de soja. Revista Brasileira de Sementes, Brasília, v.1, n.3, p.77-89, 1979.

POPINIGIS, F. Fisiologia da semente. 2.ed. Brasília: AGIPLAN, 1985. 289p.

SANTOS, O.S.; ESTEFANEL, V. Relação da altura das variedades de soja com a época de plantio e com o rendimento e sua validez como fator de caracterização varietal. Revista do Centro de Ciências Rurais, Santa Maria, v.1, n.1, p.59-83, 1971. 
SCOTT, A.; KNOTT, M. Cluster-analysis method for grouping means in analysis of variance. Biometrics, Washington D.C., v.30, n.3, p.507-512, 1974.

SEDIYAMA, C.S.; VIEIRA, C.; SEDIYAMA, T.; CARDOSO, A.A.; ESTEVÃO, H.H. Influência do retardamento da colheita sobre a deiscência das vagens e sobre a qualidade e poder germinativo das sementes de soja. Experientiae, Viçosa, v.14, n.5, p.117-141, 1972.

VAL, W.M.C.; GAUDENCIO, C.A.; GARCIA, A. Ensaio sobre época de plantio. In: Resultados da pesquisa de soja, 1984/85. Londrina: EMBRAPA-CNPSo, 1985. p.393-396.
VIEIRA, S.A.; IGNACZAK, J.C.; BEM, J.R.; VELOSO, J.A.R.O.; WENDT, W. Épocas de semeadura e espaçamento sobre algumas características agronômicas da soja no Planalto RioGrandense. Pesquisa Agropecuária Brasileira, Brasília, v.20, n.2, p.25-226, 1985.

ZUFFO, N.L.; SAKIYAMA, N.S.; SEDIYAMA, C.S.; REIS, M.S.; SILVA, R.F. Influência da época de semeadura na qualidade de sementes de soja produzidas no Mato Grosso do Sul e correlações entre os métodos de avaliação utilizados. Revista Ceres, Viçosa, v.34, n.195, p.474-487, 1987. 